\title{
Development and on-site application of new in-situ soil mixing method with ability of obstacle avoidance and inclined operation
}

\author{
Tadafumi Fujiwara ${ }^{\text {i) }}$, Hiroyasu Ishii ${ }^{\text {ii) }}$, Makiko Kobayashi ${ }^{\text {iii) }}$ and Tomoyuki Aoki ${ }^{\text {iv }}$ \\ i) Dr. Eng. Senior Research Engineer, TAISEI Corporation, 344-1, Nase-cho, Totsuka-ku, Yokohama, 245-0051, Japan. \\ ii) Senior Research Engineer, TAISEI Corporation, 344-1, Nase-cho, Totsuka-ku, Yokohama, 245-0051, Japan. \\ iii) Research Engineer, TAISEI Corporation, 344-1, Nase-cho, Totsuka-ku, Yokohama, 245-0051, Japan. \\ iv) Ph.D. Executive Chief Research Engineer, TAISEI Corporation, 344-1, Nase-cho, Totsuka-ku, Yokohama, 245-0051, Japan.
}

\begin{abstract}
Improving the ground beneath or beside existing structures is one of the most effective countermeasures against structural damage caused by seismic motion of the ground. Economical and mobile methods will be in high demand in Japan where seismic events with greater intensity are anticipated in the near future. The authors have developed a new in-situ soil mixing method using collapsible/expandable mixing blades and a special monitoring/auto-control system. This paper first describes the new technique in comparison with conventional soil mixing methods and describes the results of field tests. Lastly, an actual application is described in which a slope of loose deposits filling a valley is improved with inclined soil columns.
\end{abstract}

Keywords: ground improvement, liquefaction countermeasure, in-situ soil mixing, inclined direction

\section{INTRODUCTION}

After the 2011 earthquake off the Pacific coast of Tohoku, the importance of aseismic reinforcement for existing infrastructures has been recognized. Improving the ground beneath or beside existing structures is an effective countermeasure against future structural damage caused by seismic motion of the ground. Economical and methods ground improvement will therefore be in high demand in Japan, where seismic events of higher intensity are anticipated in the near future. The authors have developed a new in-situ soil mixing method (the WinBLADE method) comprising collapsible/expandable mixing blades and a monitoring/auto-control system (Ishii et. al. 2012). The mixing blades allow buried obstacles to be avoided during ground improvement work, because they are inserted into the ground in a collapsed state. This means that insertion does not interfere with existing facilities such as buried structures and pipe runs. The method also allows for execution at an inclined orientation because the mixing blades are relatively small and light for easy handling. The auto-control system adjusts the penetration/withdrawal rate of the mixing equipment and the rate of cement milk supply based mixing blade rotational speed. This overcomes the problem of quality variation of the solidified columns that may result from the relatively unstable motion of mixing blades driven by a smaller base machine.

In this paper, the new technique is first introduced and compared with conventional soil mixing methods. The results of field tests, in which the new method was put into use to create solidified columns in various ways, are then presented. The method was used in the actual reinforcement of a slope of loose deposition in a valley fill.

\section{NEW IN-SITU SOIL MIXING METHOD}

\subsection{Overview of the method}

A schematic view of the overall soil improvement process is given in Fig. 1. Casing pipes with an approximate diameter of $130 \mathrm{~mm}$ are driven into the ground. The collapsible/expandable mixing blades are then inserted in the collapsed state down to the lower end of the soil improvement area. In this position, the blades are expanded. The blades turn, mixing the soil, while injecting slurry, as the rod is withdrawn at a constant rate. The work is repeated in cycles for every $2 \mathrm{~m}$ of the column length (depending on the length of the steel rods). When the column is complete, the mixing blades are recovered in their collapsed state.

\subsection{Collapsible/expandable blades comprising mixing device}

A schematic view of the collapsible/expandable blades comprising the mixing device, which are the main feature of the new method, is shown in Fig. 2. The blades are expanded by the action of an internal piston that is supplied with pressurized water through the steel 


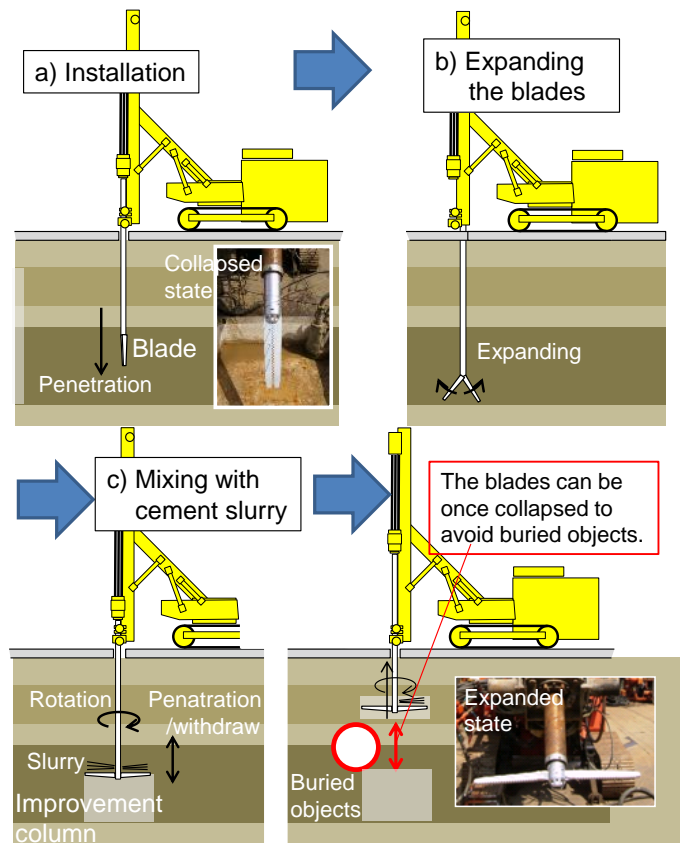

Fig. 1. Soil improvement process

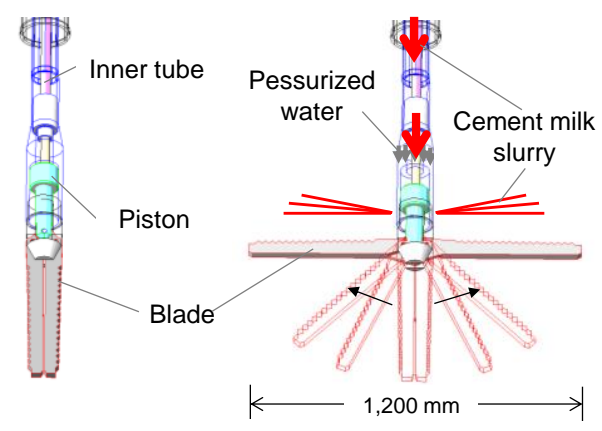

Fig. 2. Mixing blades

rods. The $1,200 \mathrm{~mm}$ expanse of the expanded blades corresponds to the diameter of the improved soil column. Cement milk slurry is supplied to the device through internal tubes within the steel rods. The cement milk inlet line connects with a piston; injection nozzles located at the base of the mixing blades open only when the piston moves fully home upon expansion of the mixing blades. This means that cement milk can be supplied only when the mixing blades are fully deployed. In actual work, this system is very useful as it provides confirmation that the mixing blades are properly expanded deep under the ground and ready for execution.

\subsection{Monitoring and auto-control system}

As described above, with the smaller size and weight of the mixing blades, the size of the construction machine has also been reduced. On the other hand, with the smaller machine size, a problem related to stability of operations with changes in ground characteristics arises because of the lower reaction force. Variations in penetration/withdrawal rate of the mixing device also become significant. This leads to concerns about quality uniformity, with possible excess or shortage in

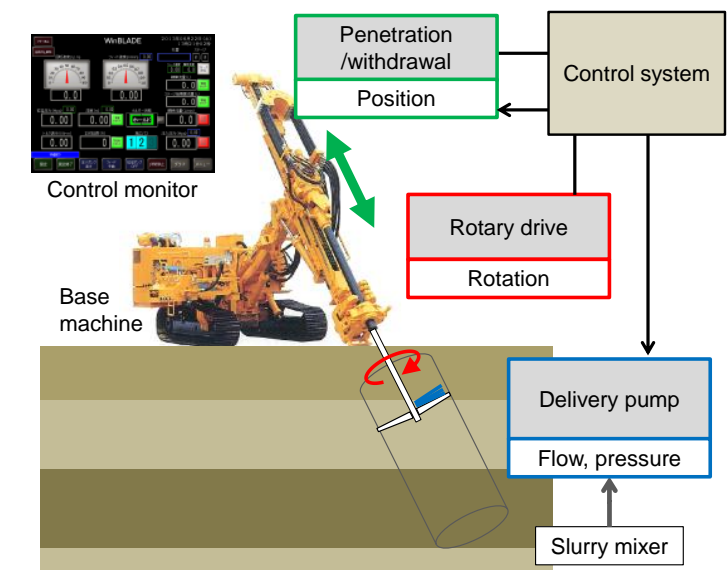

Fig. 3. Monitoring and auto-control system.

the amount of cement slurry supplied. A new control system has been developed to cope with these issues. An overview is shown in Fig. 3.

The system adjusts the penetration/withdrawal rate of the device and the supply rate of the cement slurry according to the rotational speed of the blades. For example, if the rotation rate of the blades falls when relatively hard ground is encountered, both the penetration/withdrawal rate and the supply of cement slurry are automatically reduced in order to maintain the number of rotations and the amount of cement per unit length within the planned range. As a result, these controls reduce quality variations in the solidified columns that may otherwise be caused by relatively unstable working.

\section{CONSTRUCTION TESTS IN DREDGED GROUND}

3.1 Overview of the test (10.5pt bold) (6pt spacing above)

Building on earlier tests (Ishii et. al. 2012), a series of construction tests on dredged material were carried out. Improved columns were created in both vertical and inclined directions, and the results were examined through direct observations and core samplings. The test site was an area that suffered liquefaction during the 2011 Tohoku earthquake (Urayasu City Committee, 2012). An overview is shown in Fig. 4 and outline of the test is given in Fig. 5. The ground consists of dredged material in alternating layers of cohesive soil and sandy soil down to GL-7.0m, under which there is an alluvial sand layer with about $10 \%$ fine fraction. The test conditions are listed in Table 1. Given these conditions, the cement injection rate was set at $117 \mathrm{~kg} / \mathrm{m}^{3}(\mathrm{~W} / \mathrm{C}=1.5)$ and the mixing blade rotation rate was set at 480 turns $/ \mathrm{m}$.

\subsection{Vertical ground improvement}

For the vertical test, the total depth of the improved column was $8 \mathrm{~m}$ (in four lifts of $2 \mathrm{~m}$ ). Only the lowermost lift is within the alluvial sand layer. The monitoring and control results for the third lift are 


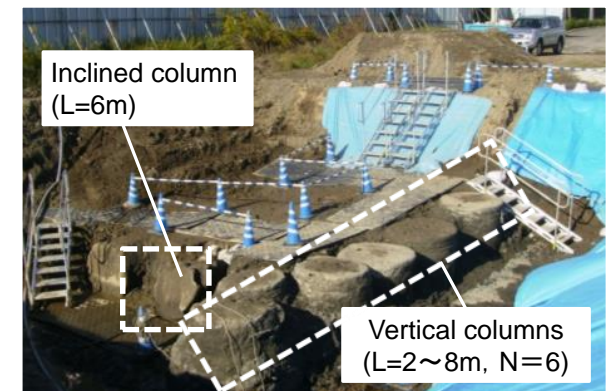

Fig. 4. Overall view of improved columns

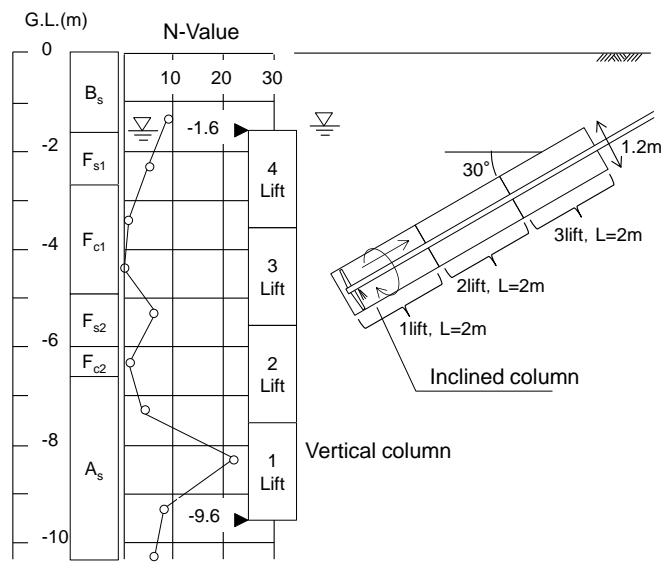

Fig. 5. Outline of the vertical and inclined columns

Table 1. Test conditions

\begin{tabular}{l|c}
\hline Rotation rate of the mixing blades & $40 \mathrm{rpm}$ \\
\hline Penetration/withdrawal rate of the mixing device & $0.5 \mathrm{~m} / \mathrm{min}$ \\
\hline Supply rate of the cement slurry & $40 \mathrm{~L} / \mathrm{min}$ \\
\hline
\end{tabular}

shown in Fig. 6. During the initial withdrawal operation, there was an instability in which the feed speed and the cement slurry supply rate were reduced to compensate for falling rotational speed. Under automatic control, stable operations continued without further speed disruption. On excavating the ground after the improved column had cured for 7 days, it was confirmed that the column had a diameter of $1.2 \mathrm{~m}$. In the area around the column, there were some scraps of wood and remains of vegetation that had apparently become mixed with the soil during reclamation. The instability noted above while operating in the dredged layer is thought to have resulted from such materials in the ground. Core samples were collected using the rotary sleeve built-in sampler for the full depth of the improved columns. The coring ratio of these samples (the proportion of core length where more than $50 \%$ of the cross-section has been solidified) is $89 \%$ overall, which is close to the $90 \%$ quality criterion (Architectural Institute of Japan 2006). The distribution of unconfined compressive strength is shown in Fig. 7. There is no significant observable variation by layer. Although the number of strength data points is small, the coefficient of variation is $30.9 \%$, which satisfies the
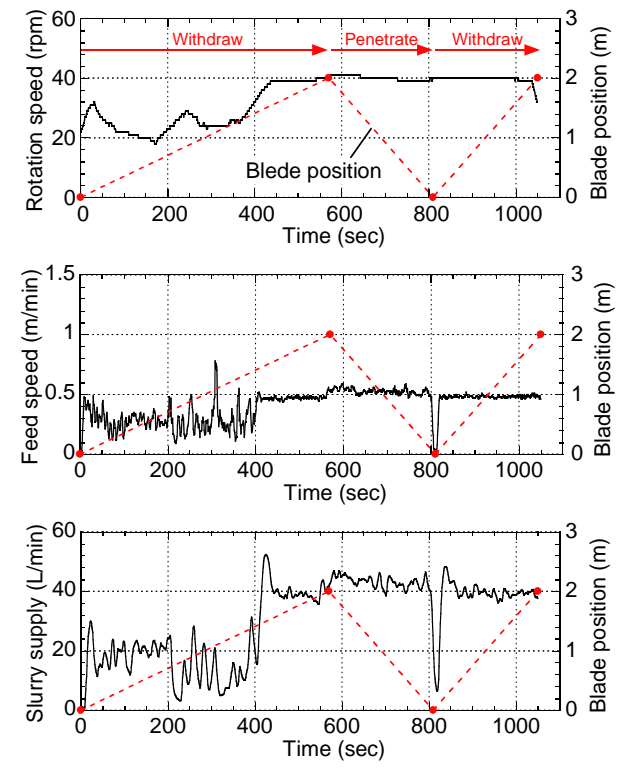

Fig. 6. Monitoring and control results

(vertical, third lift)

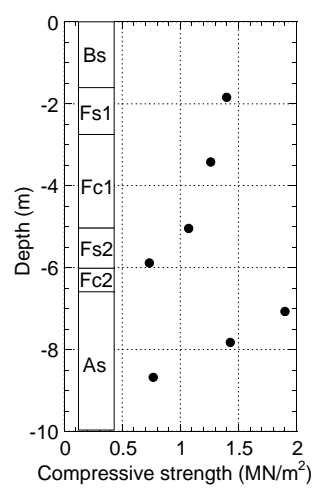

Fig. 7. Distribution of unconfined compressive strength

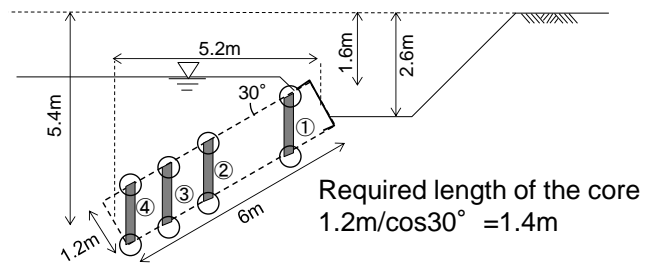

Fig. 8. Core sample verification of inclined improved column

criterion used for the conventional soil mixing method $(25-40 \%)$. For reference, the ratio of field to laboratory values of strength is about one third.

\subsection{Inclined ground improvement}

In this test, the inclined angle of drilling is $30^{\circ}$ and the total length of the improved inclined column is $6 \mathrm{~m}$ (in three lifts of $2 \mathrm{~m}$ ). The full depth of the column is within the dredged soil layer. The feed rate was modified to $0.25 \mathrm{~m} / \mathrm{min}$ during the first withdrawal operation, so the cement slurry supply was set at 20L/min to compensate. In this case, also, rotational speed fell below the planned value during the initial 


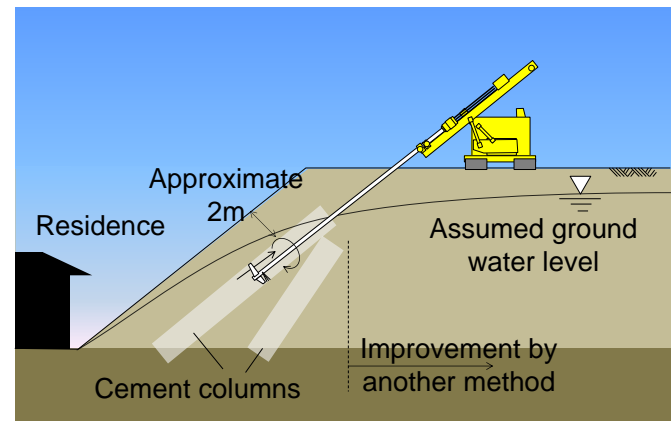

Fig. 9. Slope reinforcement work

withdrawal operation, the control system behaved just as in vertical ground improvement work. After completion, the work was verified by excavation as in the vertical case, while core samples were collected from deep areas at four points along the central axis. The four core samples included solidified sections 1.4 $m$ in length; which represents a mixed column diameter of $1.2 \mathrm{~m}$ given the $30^{\circ}$ angle, as illustrated in Fig. 8 . However, the coring ratio was only $85 \%$, which falls short of the $90 \%$ standard. This implies a requirement to set separate operational conditions, such as the number of cutting blades, when working in an inclined direction in a cohesive soil layer.

\section{APPLICATION TO A VALLEY FILL REINFORCEMENT}

The method described here was used to reinforce a slope consisting of a soft soil deposit in valley fill. A schematic cross-section of the work is shown in Fig. 9. The site is adjacent to a house, so the impact of slope collapse due to an earthquake was also a concern. Conventional methods such as soil replacement, permeation grouting and anchoring were problematic for technical reasons and the high cost. Two sets of equipment for the new method, each with a monitoring and auto-control system, were prepared. All machinery and equipment was set up on the crest of the embankment. The angle of the improved columns ranged between $35^{\circ}$ and $50^{\circ}$ and the longest column was $7 \mathrm{~m}$. A total of 150 soil mixing columns were successfully created. The worksite during construction is shown in Fig. 10. In order to improve the reliability of the work, a stirring process was added before supplying the cement slurry.

The slope surfaces were monitored for deformation during the work. The maximum vertical displacement measured was just $3 \mathrm{~mm}$ after completion of the work. As with the previous tests, the work was checked after completion by excavation and using core samples. The unconfined compression strengths of cored specimens

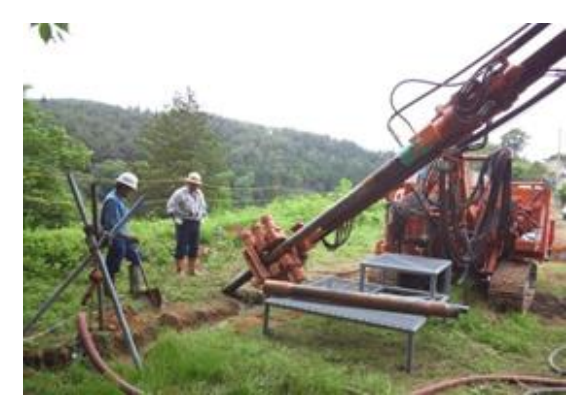

Fig. 10. Inclined improvement work in progress

satisfied the strength requirement of $600 \mathrm{kN} / \mathrm{m}^{2}$ (with a maximum strength of $3400 \mathrm{kN} / \mathrm{m}^{2}$, and a minimum strength of $660 \mathrm{kN} / \mathrm{m}^{2}$ ).

\section{CONCLUDING REMARKS}

In this paper, the effectiveness of a new in-situ soil mixing method was demonstrated by carrying out construction tests. The new method was then used to reinforce an actual slope. This practical application, to reinforce a slope in a filled valley, took advantage of the main features of the method to carry out in-situ soil mixing in an inclined direction. This work has made clear that the quality of soil improvement work depends on initial ground conditions; there is room for further optimization of the operational control system. The authors will continue work on this method with the aim of achieving soil improvement of the required quality as well as with high efficiency.

\section{ACKNOWLEDGEMENTS}

The authors gratefully acknowledge the support of the Ministry of Land, Infrastructure, Transport and Tourism of Japan in the present work (in the form of a subsidy) and Urayasu city (which provided the test site). Both forms of assistance were offered as a special case following the 2011 Tohoku earthquake.

The study is the result of joint research with Nittoc Construction Co., Ltd.

\section{REFERENCES}

1) Architectural Institute of Japan (2006) : Ground improvement design draft for building foundations (in Japanese)

2) Ishii, H., Fujiwara, T., Kobayashi, M., Aoki, T., Matsui, H., Tateishi, Y., Suga, K., Mikami, N. and Sato, J. (2012): Development of In-situ Soil Improvement Method using Collapsible Mixing Blades, Proc. of The International Conference on Ground Improvement and Ground Control, 1307-1312.

3) Urayasu city liquefaction countermeasure technology consideration investigating committee (2012): Urayasu city liquefaction countermeasure technology consideration investigation report (in Japanese). 